\title{
Simultaneous tracking of hardness, reactant conversion, solids concentration, and glass transition temperature in thermoset polyurethane coatings
}

Wang, Ting; José Segura, Juan; Graversen, Erik ; Erik Weinell, Claus; Dam-Johansen, Kim; Kiil, Søren

Published in:

Journal of Coatings Technology and Research

Link to article, DOI:

$10.1007 / \mathrm{s} 11998-020-00407-3$

Publication date:

2021

Document Version

Peer reviewed version

Link back to DTU Orbit

Citation (APA):

Wang, T., José Segura, J., Graversen, E., Erik Weinell, C., Dam-Johansen, K., \& Kiil, S. (2021). Simultaneous tracking of hardness, reactant conversion, solids concentration, and glass transition temperature in thermoset polyurethane coatings. Journal of Coatings Technology and Research, 18(2), 349-359.

https://doi.org/10.1007/s11998-020-00407-3

\section{General rights}

Copyright and moral rights for the publications made accessible in the public portal are retained by the authors and/or other copyright owners and it is a condition of accessing publications that users recognise and abide by the legal requirements associated with these rights.

- Users may download and print one copy of any publication from the public portal for the purpose of private study or research.

- You may not further distribute the material or use it for any profit-making activity or commercial gain

- You may freely distribute the URL identifying the publication in the public portal 


\title{
Simultaneous tracking of hardness, reactant conversion, solids concentration, and glass transition temperature in thermoset polyurethane coatings
}

Ting Wang ${ }^{\mathrm{a}}$, Juan José Segura ${ }^{\mathrm{b}}$, Erik Graversen ${ }^{\mathrm{b}}$, Claus Erik Weinell ${ }^{\mathrm{a}}$, Kim Dam-Johansen ${ }^{\mathrm{a}}$, Søren Kiil ${ }^{\text {** }}$

${ }^{a}$ CoaST, Department of Chemical and Biochemical Engineering, Technical University of Denmark (DTU), Building 229, DK-2800 Kgs. Lyngby, Denmark.

${ }^{\mathrm{b}}$ Hempel A/S, Lundtoftegårdsvej 91, DK-2800 Kgs. Lyngby, Denmark

\begin{abstract}
In this work, the curing and hardness evolution of a two-component polyurethane (PU) coating in four different environments, three of which were solvent evaporation-suppressed conditions, were studied.

In contrast to previous studies, the simultaneous use of Fourier-transform infrared spectroscopy, gravimetric analysis, and pendulum hardness, allowed a transient mapping of the degree of isocyanate conversion, solids concentration, and coating hardness. Furthermore, to explore in more detail the coupling of the underlying mechanisms, the evolution in the average coating glass transition temperature was estimated by dynamic mechanical analysis, and the data simulated using the so-called Kelley-Bueche equation.

For the curing conditions investigated, the final coating hardness differed by a factor of two, with the lowest values obtained for the evaporation-suppressed conditions. Due to the isocyanate groups reaching full conversion for all four series, the reason for the lower hardness was attributed entirely to the plasticizing effect of residual solvent. Using a $\mathrm{K}_{\alpha}$ value of 0.687 in the Kelley-Bueche equation, the coating glass transition temperature as a function of the PU volume fraction could be successfully simulated, and was found to increase from about $282 \mathrm{~K}$ at a volume fraction of 0.79 to $319 \mathrm{~K}$ at one of 0.93 . In addition, when the experimental temperature was lower than the coating glass transition temperature, a proportional increase of the pendulum hardness with the reciprocal loss factor was seen.
\end{abstract}

\footnotetext{
*Corresponding author. E-mail address: sk@kt.dtu.dk
} 
The effects of catalyst concentration in the coating were also investigated, and this parameter was found to have a strong influence on both the surface conversion, the solids concentration, and the coating hardness. A too fast curing rate shortens the time to vitrification, after which the solvent evaporation rate becomes diffusion-controlled and very low, leading to higher residual solvent contents and significantly lower hardness values.

The results obtained provide guidelines for how to optimize ventilation conditions during the curing of solvent-based, thermoset PU coatings.

\section{Keywords}

Polyurethane, Solvent, Hardness, Glass transition temperature, Organotin catalyst

\section{Introduction}

High-performance, organic coatings are widely applied to prevent corrosion of steel structures, such as ships, wind turbines, bridges and oil rigs. Due to environmental concerns, the solventfree or water-based coatings are becoming increasingly popular in most sectors, but in the heavyduty industries, where large structures are often coated under conditions of high humidity (tropical areas), solvent-based coatings still play a very important role.

A solvent-based coating formulation consists of binders, pigments, fillers, additives and solvents ${ }^{1}$, and the curing reaction between binder(s) and curing agent(s) results in a threedimensional network structure, providing barrier properties to the coating. Organic solvents, present in the formulation, help to dissolve components of the coating formulation and promote efficient mixing of the resin and the curing agent during the application ${ }^{2}$. Solvents also lower the viscosity of the liquid coating to allow proper application by spraying ${ }^{1}$. Despite these advantages, solvents can have negative effects on the coating properties when trapped inside the coating system after completion of the curing process. Residual solvents can reduce the hardness, glass transition temperature, and mechanical moduli of the coating system, which all together undermine the desired mechanical and anti-corrosive properties ${ }^{2,3}$. In so-called evaporation-suppressed environments, the solvent concentration in the air goes up over time, which significantly slows down the solvent evaporation rate and prolongs the curing time. Under such conditions, the amount of residual solvents in the coating increases. Examples include coating application inside ballast tanks, so-called painting shelters or other confined 
spaces $^{4}$, or inside a paint shop without proper ventilation (e.g. limited ventilation during nonactive periods).

Two-component PU coatings are known for their outstanding chemical resistance and excellent weather resistance and they are commonly applied as topcoats for UV radiation protection of underlying coating layers. Factors like temperature, air velocity, relative humidity (RH), and solvent concentration in the surrounding environment, play an important role for the curing of these coatings, especially in an evaporation-suppressed environment. However, this is not a wellresearched area.

Esmaeilpour et al. ${ }^{5}$ investigated the surface characteristics of PU coatings under different curing conditions in a closed box. Due to the slower solvent evaporation rate, films cured for 20 days had a lower roughness and contact angle than samples cured for 10 days under ambient conditions. Vessot et al. ${ }^{6}$, on the other hand, studied the effect of temperature and substrate type on the curing of two-component PU-based coatings. They observed that the full conversion of the isocyanate group took more than one hour at temperatures below $100{ }^{\circ} \mathrm{C}$. When the coating was applied on a steel substrate, as opposed to a sheeting molding compound (SMC), a faster curing reaction was measured, which was attributed to the high thermal conductivity of the steel plate (a faster reaction temperature increase). In addition, the porous nature of the SMC substrate caused an ingress of solvents and reactants from the coating system, which also reduced the rate of curing reaction.

Huang et al. ${ }^{7}$ explored the influence of resins with different acid values and temperature on the curing of PU coatings using the pendulum hardness test. The increase of curing temperature and acid value of the resin accelerated the increase in the coating pendulum hardness, but the final hardness, due to very similar crosslinking densities, was the same. Shekhar et al. ${ }^{8}$ studied the curing of a solvent-based epoxy coating in the environment of a sub-ambient temperature or high RH. They concluded that a low temperature or a high RH resulted in an increase of the drying time of epoxy coatings, giving poor adhesion to the substrate and scratch resistances. In the environment of high $\mathrm{RH}$, the presence of polar water molecules interferes and reduces coating adhesion to the substrate. Kiil ${ }^{4}$ developed a model to simulate, amongst other, the influence of wind velocity and bulk air concentration of solvent on the curing process of a thermoset PU coating, and compared the results to experimental data obtained by Dušková-Smrčková and Dušek $^{9}$. Simulations showed that a lower wind velocity or higher bulk air concentration of 
solvent (less than $10 \%$ of the saturated vapor concentration of solvent) caused longer drying time, but also that the final solvent retentions were practically the same.

In this work, with the aim of providing practical guidelines and study the underlying mechanisms, the curing of a PU coating under suppressed ventilation (evaporation) conditions was studied. Compared to previous investigations, we have sought to provide a complete transient analysis, including coating hardness, reactant conversion, solids concentration, and coating glass transition temperature.

\section{Overview of the mechanisms underlying simultaneous solvent evaporation and chemical curing of a thermoset PU coating}

Solvent evaporation and chemical curing are strongly coupled processes in the formation of a thermoset coating layer. A two-stage curing process has commonly been used to describe the film formation process ${ }^{3,4,10}$. In stage 1 , where coating components have full mobility, the rate of solvent evaporation is more or less constant and determined by the external mass transport of solvent, whereas the rate of curing is controlled by the intrinsic chemical properties of reactants and catalyst. As solvent evaporates and binders cross-link, gelation, at some point in time, takes place when the first insoluble infinite molecule is formed and the viscosity becomes infinite ${ }^{3,11}$. The so-called vitrification phenomenon, on the other hand, which has been shown to cause an increase in the solvent diffusion resistance ${ }^{3,10}$, begins when the glass transition temperature of the film becomes equal to the curing temperature, thereby initiating stage 2 . During this stage, the solvent evaporation rate rapidly drops and becomes intrafilm diffusion-controlled, and the rate of curing is dominated by the segmental mobility of reactive groups.

The initial rate of solvent evaporation depends entirely on the vapor pressure of the pure solvent(s), but the binder-solvent interaction becomes more important as the curing reaction progresses towards high degrees of curing. This explains why methyl amyl ketone (MAK) has lower initial evaporation rate than methyl ethyl ketone (MEK), but a higher final solid weight fraction when used as solvent in a thermoset PU coating ${ }^{9}$. MAK has a higher solvent activity that MEK and thus a higher evaporation rate during the diffusion-controlled stage 2 . The crosslinking reaction and the solvent evaporation are strongly coupled in that a high cross-linking reaction rate can result in an increase in residual solvent. This is because the fast curing reaction reduces the segmental mobility of the coating system, which shortens the time until stage 2 
begins. Hence, Dušková-Smrčková and Dušek ${ }^{9}$ observed a higher solvent retention when a high catalyst concentration was used in a PU formulation.

\section{Experimental}

\section{Sample preparation}

A polymeric polyol (HEMPATHANE HS 55619) (Base) and 1,6-hexamethylene diisocyanate (HEMPEL'S CURING AGENT 97050) (CA) were supplied by Hempel A/S, Denmark. The PU coating was prepared with a mixing weight ratio of CA/Base of 0.109 (small excess of isocyanates). The solids concentration of the PU formulation is $76.7 \mathrm{wt} \%$, of which $16.5 \pm 2.7$ wt $\%$ is naphtha (light C9 aromatic petroleum). The remaining is a mixture of additional solvent (e.g., xylene and n-butyl acetate). The catalyst in the PU formulation was dibutyltin dilaurate (DBTDL). Calcium carbonate $\left(\mathrm{CaCO}_{3}, \geq 97 \mathrm{wt} \%\right)$ was used as a filler in a concentration of 9.1 $\mathrm{wt} \%$ in the PU formulation.

Using a Baker film applicator with a gap size of $100 \mu \mathrm{m}$ and a width of $80 \mathrm{~mm}$, the coating was applied on a glass panel of $100 \mathrm{~mm} \times 150 \mathrm{~mm}$ by drawdown application. The coating films were cured under different transient conditions as specified below. The initial wet film thickness (WFT) was approximately $70 \mu \mathrm{m}$ (as a rule of thumb taken as $70 \%$ of the applicator gap of 100 $\mu \mathrm{m}$ ) and the final dry film thickness (DFT) was approximately $50 \mu \mathrm{m}$ with a volume solids ratio of $67 \%$.

To obtain free PU films, the formulations were cured on polypropylene substrates and first cured

in the climate room (CR) (see later) condition for two weeks and then post-cured at $60{ }^{\circ} \mathrm{C}$ for 48 hours. Using an Elcometer 355 coating thickness gauge, the final DFT was measured to $162.4 \pm$ $4.8 \mu \mathrm{m}$ and the solids concentration to $96.8 \mathrm{wt} \%$.

\section{Curing conditions}

The PU coatings were cured in a climate room at $23.2 \pm 0.1{ }^{\circ} \mathrm{C}$ and the RH $54.5 \pm 1.1 \%$. Four different curing conditions, provided in Table 1, were established. In the CR condition, coatings were cured without any restrictions. In the closed container (CC) condition, two coated panels were placed in a closed three-liter plastic container covered with a lid, which simulates the inadequate ventilation condition found in a closed environment where the air velocity is close to $0 \mathrm{~m} / \mathrm{s}$ (only natural convection takes place). The CC-CR condition approaches a real-life 
ventilation condition in the industry where coatings are first cured in the paint shop with low ventilation for the first day and then moved outside into the open air. In the CC-Naphtha condition, a certain amount of naphtha (specified below) was placed in a small cup inside the container, next to the coating sample. The CC-Naphtha condition ensured that additional solvent evaporated and suppressed the evaporation of solvent from the PU films. This environment was established to study the influence of trapped solvent on the hardness of the cured PU films.

Table 1. The four different curing conditions used in the experiments. $\mathrm{CR}=$ Climate Room, $\mathrm{CC}=$ Closed Container.

\begin{tabular}{cl}
\hline $\begin{array}{c}\text { Curing } \\
\text { condition }\end{array}$ & Description \\
\hline CR & Coated panels cured in the climate room. \\
CC-CR & $\begin{array}{l}\text { Two coated panels cured for one day in a closed container, followed by curing } \\
\text { in the climate room. }\end{array}$ \\
CC & $\begin{array}{l}\text { Two coated panels cured in a closed container. } \\
\text { CC-Naphtha }\end{array}$ \\
$\begin{array}{l}\text { Two coated panels cured in a closed container in the presence of a specified } \\
\text { amount of naphtha (in separate pitch). }\end{array}$ \\
\hline
\end{tabular}

\section{Experimental procedures}

Five series of experiments were performed in this work. In the first, the effects of curing conditions on hardness were studied for PU films cured under the CR, CC-CR and CC conditions for 14 days, while conducting weight measurements, FTIR spectroscopy, and hardness measurements. An analytical balance from Sartorius (ENTRIS623I-1S), with an accuracy of $0.001 \mathrm{~g}$, was used for the weight loss measurements. The influence of residual solvent on the mechanical properties was investigated. In the second series, a total of eight groups of PU films were cured for seven days under the CR, CC and CC-Naphtha conditions. Under the CCNaphtha condition, the amount of additional solvent present in the container was $0.1,0.2,0.4$, $0.8,1.0$ and $2.0 \mathrm{~g}$, corresponding to $0.06,0.15,0.23,0.53,0.68$ and $1.15 \mathrm{~g}$ naphtha/(g initial wet coating), respectively, for a WFT of approximate $70 \mu \mathrm{m}$ and a surface of approximate $100 \mathrm{~cm}^{2}$. In the third series, PU films were first cured for 14 days under the CC-Naphtha conditions (1.27 g naphtha/(g initial wet coating $)$ ) and then heated to $60^{\circ} \mathrm{C}$ in an oven for various time intervals to remove the residual solvent and subsequently cooled for $30 \mathrm{~min}$. In the fourth series, the free 
rectangular PU films $(3.0 \mathrm{~mm} \times 1.0 \mathrm{~mm})$ were first immersed in naphtha for one hour and then taken out for drying at various times to remove residual solvent. At this point in time, the dynamical properties were measured. In the last series, the catalyst concentration was varied $(0$, 70,350 and $1000 \mathrm{ppmw}$ ) to study the effect of this parameter on the curing of the PU coating.

\section{FTIR spectroscopy of the coating samples}

Using a Thermo Scientific Nicolet iS5 FTIR spectrometer equipped with iD7 attenuated total reflectance (ATR) diamond crystal, ATR-FTIR spectra were collected. A total of eight scans were performed in the range of 500 to $4000 \mathrm{~cm}^{-1}$ with a resolution of $4 \mathrm{~cm}^{-1}$ for each FTIR spectrum. The FTIR spectra in each PU film were collected at two positions.

From the disappearance of the isocyanate peak at $2273 \mathrm{~cm}^{-1}$, the FTIR spectra could be used to obtain the isocyanate conversion degree. The peak at $875 \mathrm{~cm}^{-1}$, attributed to out of plane bending

of carbonate ions from calcium carbonate ${ }^{12,13}$, was used as a reference (Ref). The amount of calcium carbonate is constant during the curing reaction, and thereby useful as an internal standard. The isocyanate surface conversion was calculated as follows:

$$
\mathrm{X}_{\mathrm{NCO}}=\left(1-\frac{A_{\mathrm{NCO}, t} / A_{\mathrm{Ref}, t}}{A_{\mathrm{NCO}, t_{0}} / A_{\mathrm{Ref}, t_{0}}}\right)
$$

where $A_{\mathrm{NCO}, t_{0}}$ and $A_{\mathrm{Ref}, t_{0}}$ are the initial area of the NCO peak and the Ref peak, respectively, and $A_{\mathrm{NCO}, t}$ and $A_{\mathrm{Ref}, t}$ are the area of NCO peak and Ref peak at time $t$, respectively. When neglecting side reactions, the isocyanate conversion can be taken as the curing degree of the PU coating.

\section{Pendulum hardness measurements}

The hardness of the PU films on glass panels was measured with a Pendulum Hardness Tester Model 299/300 from ERICHSEN according to the König method (DIN ISO 1522) ${ }^{14}$. During a measurement, the pendulum was placed at the coating surface and deflected $6^{\circ}$, whereafter the pendulum was released and the number of swings recorded for the amplitude of swing to decrease from $6^{\circ}$ to $3^{\circ}$. The time for the amplitude of swing to decrease was calculated by multiplying the number of swings by $1.4 \mathrm{~s}$ (the period of an oscillation for the König method). This time is taken as the hardness of the coating. 


\section{Dynamic mechanical analysis}

Using a rheometer DHR-2 (TA Instruments) with a Film/Fiber Tension geometry, a dynamical mechanical analysis (DMA) was performed on free PU films. Scans were run at a rate of $5{ }^{\circ} \mathrm{C} / \mathrm{min}$ under $25 \mu \mathrm{m}$ axial displacement at a frequency of $1 \mathrm{~Hz}$.

\section{Results and discussion}

The effects of curing conditions, residual solvent concentration, and catalyst concentration on the mechanical properties of the PU coatings were investigated and will be presented in the coming paragraphs.

\subsection{FTIR analysis}

In the curing process of PU films, isocyanate and hydroxyl groups are consumed, while a urethane group is formed (Scheme 1).

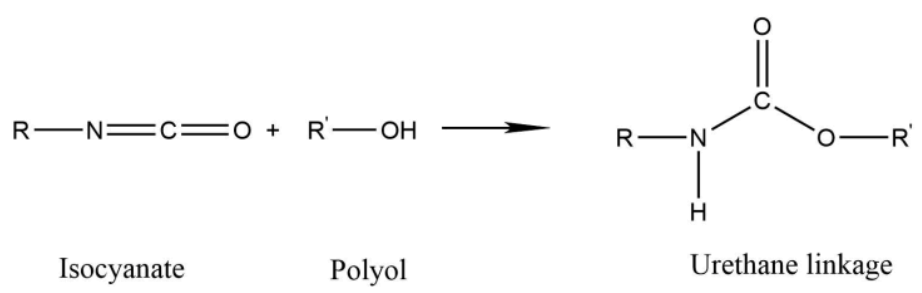

Scheme 1. Cross-linking reaction of an isocyanate and a polyol to form a urethane linkage. $\mathrm{R}$ and R' symbolize alkyl or aryl groups.

As illustrated by FTIR spectra in Fig. 1, a pronounced peak at $2273 \mathrm{~cm}^{-1}$, due to the NCO asymmetric stretching $\left(v_{\mathrm{a}}-\mathrm{N}=\mathrm{C}=\mathrm{O}\right)$ and a broad hydroxyl stretching vibration $(v-\mathrm{OH})$ peak at $3500 \mathrm{~cm}^{-1}$, is observed to decrease with the progress of the curing reaction, indicating the consumption of reactants, whereas the amine stretching vibration peak $(v-\mathrm{NH})$ at $3370 \mathrm{~cm}^{-1}$ increases due to the formation of urethane groups ${ }^{15-17}$. As expected, the Ref peak $\left(v-\mathrm{CO}_{3}^{2-}\right)$ area at $875 \mathrm{~cm}^{-1}$ stays almost constant during the curing process. The initial absorbance intensity (at time zero) is lower than the later absorbance intensity; this is caused by the high solvent content at time zero. After curing for 14 days, the isocyanate peak disappears, implying the completion of the curing reaction. 


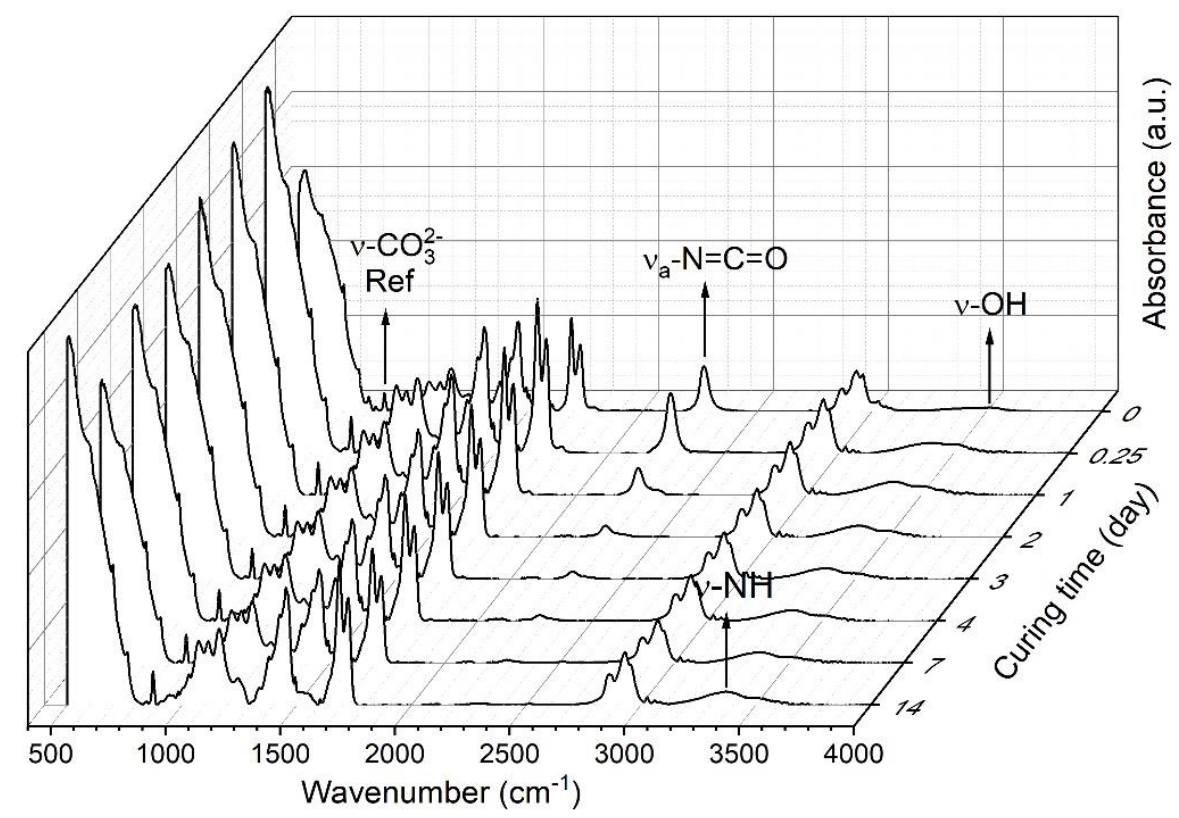

Fig. 1: ATR-FTIR spectra of the PU film on glass cured under the climate room (CR) condition.

\subsection{Effect of curing conditions on hardness}

To investigate the influence of curing conditions on the curing process, PU films were cured under the CR, CC-CR and CC conditions (see Table 1 for abbreviations). Under the CR condition, the evaporation of solvent is fast in in the first six hours and then decreases to a much lower value as shown in Fig. 2(a). 
(a)

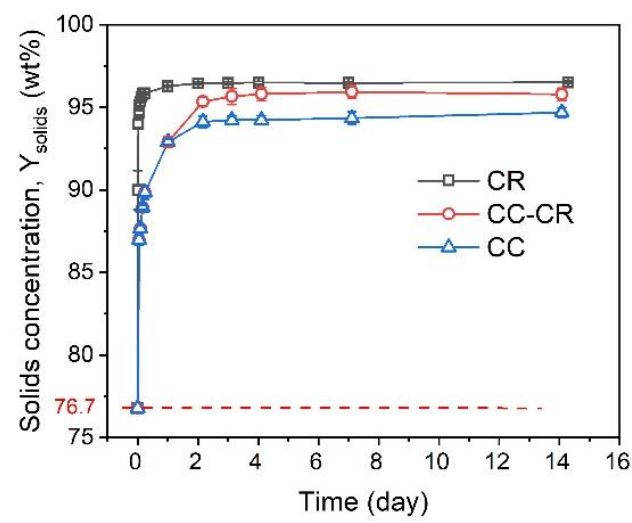

(b)

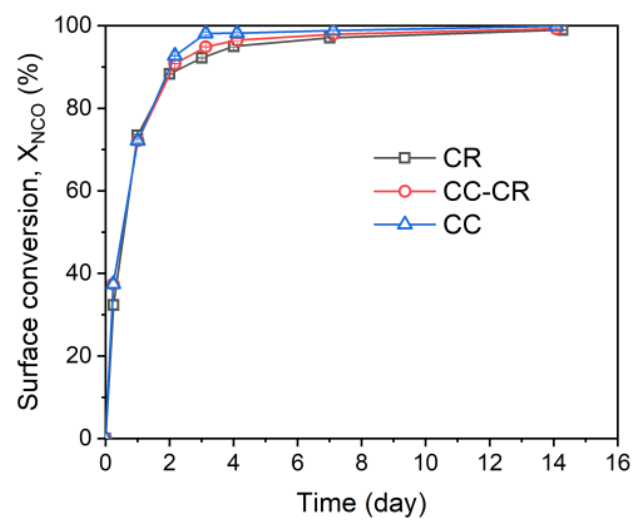

(c)

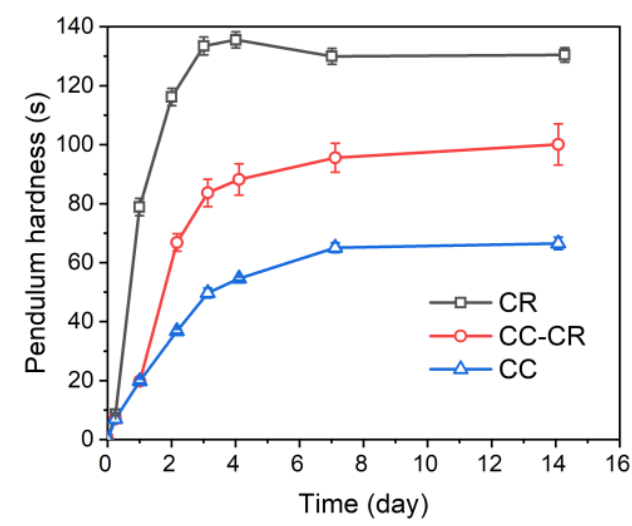

Fig. 2: Curing of PU films under different curing conditions: (a) The increase of solids concentration during solvent evaporation, (b) The surface conversion of isocyanate groups in the coating, and (c) The hardness development of the coating. The data for the CR and CC-CR conditions was obtained from the one group of PU films with various curing times, while the data for the $\mathrm{CC}$ condition was obtained from a total of seven groups of PU films with various curing times. The standard deviation is shown with error bars in all three plots. 
The solids concentration stabilizes at $96.5 \mathrm{wt} \%$. When comparing the solids concentration curves under the three curing conditions, it can be seen that more solvent is trapped inside the PU film when the ventilation condition becomes more severe. When cured under the CC-CR condition, the PU films continuously lose weight within the first two days. The final solids is about 95.8 wt \%, which is $0.7 \mathrm{wt} \%$ less than that of samples cured in the CR condition. When cured under the CC condition, the final solids concentration is $94.7 \mathrm{wt} \%$, which is about $1.8 \mathrm{wt} \%$ lower than the CR condition. The evaporation-suppressed condition leads to the trapping of solvent inside the film.

As shown in Fig. 2(b), the initial isocyanate consumption rate is faster within the first day and then gradually slows down. This is due to the high initial concentration and mobility of reactants ${ }^{11}$. When it comes to the curing rate under different conditions, the evaporationsuppressed condition helps to boost the curing reaction of the PU films. The latter have a similar conversion rate of isocyanate groups initially (see Fig. 2(b)), but after two days, the PU film has the highest conversion when cured under the $\mathrm{CC}$ condition. This can be explained by an increased consumption of isocyanate groups because of the improved polymer segment mobility as more residual solvent is trapped, as seen in Fig. 2(a). Whatever the curing condition is, the final isocyanate conversion reaches about $100 \%$ after curing for two weeks. As the conversion of the isocyanate groups in the surface layer is lower than in the bulk ${ }^{9}$, it can be concluded that the PU film was fully cured after 14 days. This indicates that the curing condition has an insignificant impact on the final curing degree.

Looking at Fig. 2(c), it can be seen that the pendulum hardness of PU films increases rapidly during the first three days when the solvent evaporates and curing reaction proceeds. As the solvent evaporation "completes" during the first two days and the isocyanate conversion becomes close to $100 \%$ after three days, the hardness development of the PU films becomes stable. The final hardness is greatly influenced by the curing conditions, and the hardness of PU films cured under the CR condition is about twice as high as films cured in the CC condition. Due to the observation that the isocyanate conversion under the three conditions all eventually reaches $100 \%$, the final hardness of the PU films must be determined by the amount of residual solvents inside the films only. The higher the residual solvent content, the softer the PU films become. In other words, the residual solvent works like a plasticizer. Consequently, higher hardness is obtained when less solvent is trapped inside the PU film. 
Before the vitrification of the film (so-called stage 1 behavior $^{3}$ ) sets in, the rate of solvent evaporation is controlled by the external mass transport of solvent, and the driving force of the evaporation process can be quantified based on the solvent partial pressure difference across the film-air interface. After curing for six hours, the solids concentration is $89.4 \pm 0.4 \mathrm{wt} \%$ (CC-CR and $\mathrm{CC}$ in Fig. 2(a)) and the corresponding vapor pressure of the solvent inside the three-liter container was estimated to be $372 \mathrm{~Pa}$ at $20^{\circ} \mathrm{C}\left(376 \mathrm{~Pa}\right.$ at $\left.23.2^{\circ} \mathrm{C}\right)$, that is $93.0 \%$ of the saturated vapor pressure, where the concentration gradient is greatly reduced due to the accumulation of the solvent inside the container. This significantly reduces the rate of solvent evaporation from the PU film. However, in the CR condition, the evaporated solvent can be effectively removed from the air-film interphase without hindering the solvent evaporation process. Therefore, the evaporation-suppressed condition leads to a reduction of the driving force of the evaporation process and thereby increases the trapping of solvent in the PU film.

With the increase of curing degree and evaporation of solvent, the PU films start to vitrify when the glass transition temperature of the film becomes equal to the curing temperature. In Fig. 2, after curing for two days, when the isocyanate conversion is about $90 \%$ and the solids concentration is higher than $93.0 \%$, all PU films start to vitrify. In stage 2, the solvent evaporation becomes intrafilm diffusion-controlled and the rate is significantly reduced because of mobility restriction of the coating network ${ }^{3,4}$. Therefore, even though the PU films were taken out from the container after one day for the CC-CR condition, the rate of solvent evaporation slows down as the curing degree is very high after one day and the films have entered stage 2 after two days. The trapping of solvent can in turn affect the curing process. During stage 1, the solvent retention has limited effect on the curing reaction as indicated by the similar curve shape in stage 1 (first two days) in Fig. 2(b). However, the curing reaction rate becomes different during stage 2 . The increased rate in the evaporation-suppressed conditions shortens the time prior to stage 2, thereby further suppressing the solvent evaporation process.

\subsection{Effect of residual solvent concentration on the mechanical properties}

\section{Pendulum hardness}

In order to further verify the reduction of hardness caused by the residual solvent, two groups of experiments were performed. In the first experiment, additional naphtha was introduced into the gas phase environment (CC-Naphtha condition). As can be seen in Fig. 3(a), the solids 
concentration decreases (equivalent to more residual solvent in the coating) with the increasing amount of naphtha.

(a)

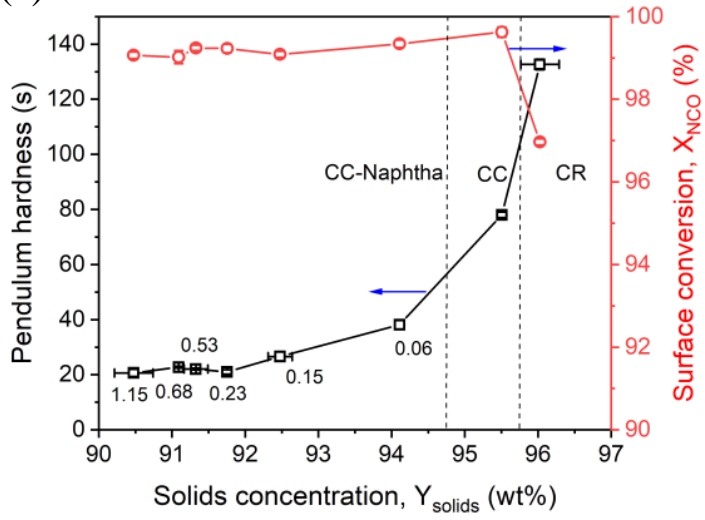

(b)

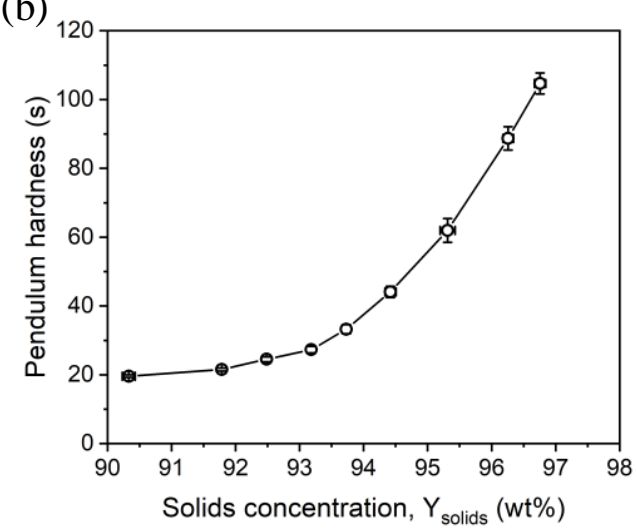

Fig. 3: (a) The pendulum hardness and the surface conversion of isocyanate groups (Series 3) versus solids concentration of the coating under different curing conditions (the three curing conditions and the additional naphtha contents (g liquid naphtha/(g initial wet coating)) are shown together with the data points); (b) The increase in pendulum hardness after the removal of residual solvent by heat-treatment at $60{ }^{\circ} \mathrm{C}$ (Series 4). Standard deviations are shown with error bars in both plots.

When $1.15 \mathrm{~g}$ liquid naphtha/(g initial wet coating) was added to the container environment, there was still some solvent left in the cup after seven days, suggesting a vapor saturation inside the container. Under the CR condition, the film has the highest hardness even though the curing degree is about $2 \%$ lower than that cured under the inadequate ventilation conditions. The isocyanate conversion is about $99 \%$ when cured under the CC and CC-Naphtha conditions, so that the influence of PU curing on the hardness can be neglected. It is clearly seen that the hardness of PU film rises with less residual solvent. In addition, an induction period can be observed where the hardness does not increase when the solids is lower than $92.5 \mathrm{wt} \%$. In the induction period, the content of solvent retention does not influence the hardness and the value of hardness is determined by the curing degree.

In the second experiment, the PU films were pre-cured in the CC-Naphtha condition for 14 days instead of seven days so that the PU curing reaction was complete, excluding the influence of curing. As shown in Fig. 3(b), heat treatment can effectively remove the residual solvent and 
increase the hardness of the PU coating. Therefore, the hardness can be improved by removing the residual solvent. Furthermore, the results of Fig. 3(b) are in agreement with those of Fig. 3(a); harder films are obtained with less residual solvent.

\section{Dynamic mechanical analysis}

To determine the effects of the residual solvent on viscoelastic properties of the PU coating, DMA measurements were performed on PU free films. The thickness of these films was approximately three times that of the PU films on the glass panel. Being a bulk property, the coating average glass transition temperature is expected to be uninfluenced by the thickness, that is to say, the PU films should have the same glass transition temperature when their solids concentration and curing degree are the same. Therefore, the DMA results of the PU free films can be used to elucidate the glass transition temperature of a sample with a lower thickness, but the same solids concentration and curing degree. In Fig. 4, storage modulus and loss factor against temperature and as a function of solids concentration are plotted.

(a)

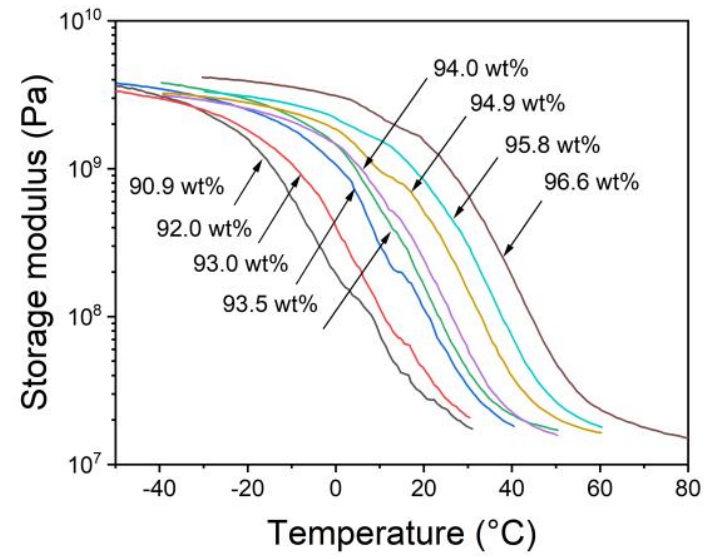

(b)

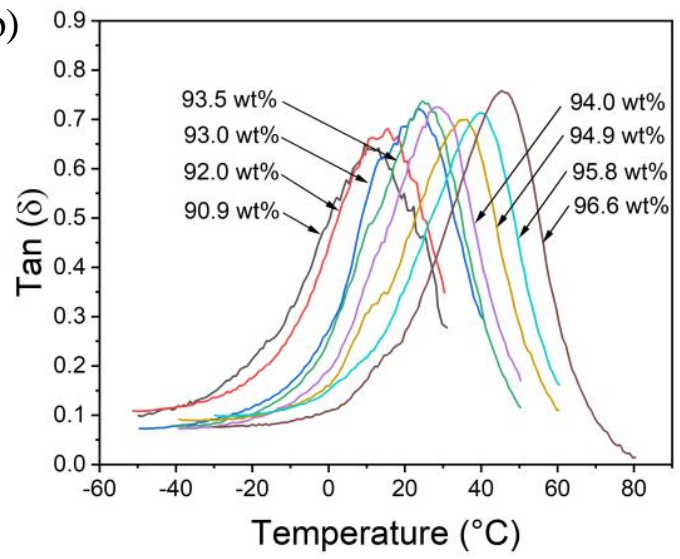

Fig. 4: DMA results of the PU free films with different solids concentration: (a) storage modulus and (b) loss factor $(\tan (\delta))$.

It can be seen in Fig. 4(a) that PU films with different solids concentration have similar storage modulus in both glassy and rubbery regions, suggesting that the increase of residual solvent has an insignificant influence on the elasticity in the glassy or rubbery regions. This may be attributed to the non-polar naphtha not being able to alter the hydrogen bonding interaction between polymer chains. However, a polar solvent, e.g. water, was reported to greatly decrease 
the storage modulus of an epoxy resin ${ }^{18,19}$ because the presence of water disrupts the interchain hydrogen bonds in the epoxy resin. In Fig. 4(b), with the increase of the solids concentration, the peak of $\tan (\delta)$ shifts to higher temperature and the peak height is slightly increased. This is due to the plasticizing effect of the solvent on the PU coating.

Following the method of Berry et al. and Nogueria et al. ${ }^{18,19}$, the glass transition temperature was determined from the peak position of the tan $(\delta)$ curve and the results are shown in Fig. 5, where the glass transition temperature is seen to be nearly proportional to the solids concentration.

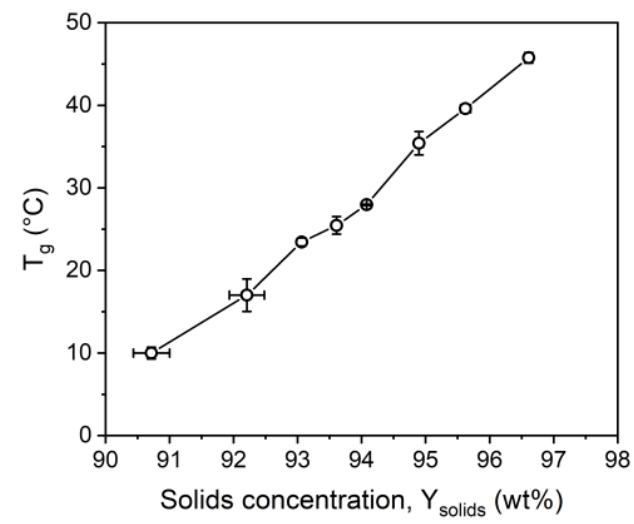

Fig. 5: The transient change of the average glass transition temperature against the solids concentration of the free PU films (16 samples in total were used for the plot). The standard deviations are shown with error bars.

The low-molecular-weight solvent disrupts the interchain Van der Waals force resulting in an increased chain segment mobility, thereby decreasing the glass transition temperature. In Fig. 5, the solids concentration is about $93.0 \mathrm{wt} \%$ when the glass transition temperature is equal to $23.2{ }^{\circ} \mathrm{C}$ (the curing temperature). This solids concentration is regarded as the onset of the vitrification when the PU film is fully cured. This confirms the vitrification point observed in Fig. 2, where the solids concentration should be higher than $93.0 \mathrm{wt} \%$ when the curing degree is about $90.0 \%$. This also explains the induction period observed in Fig. 3(a) and (b) at a solids concentration lower than $93.0 \mathrm{wt} \%$; hardness barely increases when the coating is in the rubbery state.

The Kelley-Bueche equation ${ }^{20}$, derived from the free volume model, is widely used to estimate the glass transition temperature of polymer-diluent systems: 


$$
T_{\mathrm{g}, \mathrm{m}}=\frac{\left(1-\phi_{\mathrm{p}}\right) T_{\mathrm{g}, \mathrm{s}}+K_{\alpha} \phi_{\mathrm{p}} T_{\mathrm{g}, \mathrm{p}}}{1-\phi_{\mathrm{p}}+K_{\alpha} \phi_{\mathrm{p}}}
$$

where $\phi_{\mathrm{p}}$ is the polymer volume fraction, $K_{\alpha}$ is the ratio of the thermal-expansion coefficient of polymer to solvent, and $T_{\mathrm{g}, \mathrm{s}}$ and $T_{\mathrm{g}, \mathrm{p}}$ are the glass transition temperature of the solvent and solvent-free polymer, respectively.

The influence of a non-polar solvent on the polymer network can be described by the free volume theory, whereas the solvent-polymer interactions should be taken into account for polar solvents like water ${ }^{19,20}$. Therefore, the Kelley-Bueche expression is suitable for estimation of the glass transition temperature of the PU-naphtha mixture, $T_{\mathrm{g}, \mathrm{m}}{ }^{3,21}$. The glass transition temperature of naphtha $\left(T_{\mathrm{g}, \mathrm{s}}\right)$ was calculated from the following equation 3

$$
T_{\mathrm{g}, \mathrm{s}}=T_{\mathrm{m}, \mathrm{s}}\left(0.6+3 \cdot 10^{-4} M_{\mathrm{w}, \mathrm{s}}\right)
$$

where the melting point of naphtha, $T_{\mathrm{m}, \mathrm{s}}$, is $203.5 \pm 25.9 \mathrm{~K} 22$ and $M_{\mathrm{w}, \mathrm{s}}$ of naphtha is $120 \mathrm{~g} / \mathrm{mol}$. The estimated $T_{\mathrm{g}, \mathrm{s}}$ is $131.9 \pm 16.7 \mathrm{~K}$. Equation 2 was used to simulate the experimental data using the least-squares method where $T_{\mathrm{g}, \mathrm{s}}$ was fixed at $131.9 \mathrm{~K}, T_{\mathrm{g}, \mathrm{p}}$ initially set to $337.1 \mathrm{~K}$, which was obtained by linear extrapolation of experimental data when $\phi_{\mathrm{p}}=1.0$, and $K_{\alpha}$ was initially taken to $0.545^{3}$. In Fig. 6, comparisons of simulation and experimental data are shown. A reasonably good agreement can be seen. The fitted value of $T_{\mathrm{g}, \mathrm{p}}$ is $339.4 \mathrm{~K}$ and is quite close to the linear extrapolated value. The satisfactory agreement verifies the assumption of the additivity of free volume for the PU-naphtha system ${ }^{23}$. The free volume added by the residual solvent reduces the glass transition temperature of the system. 


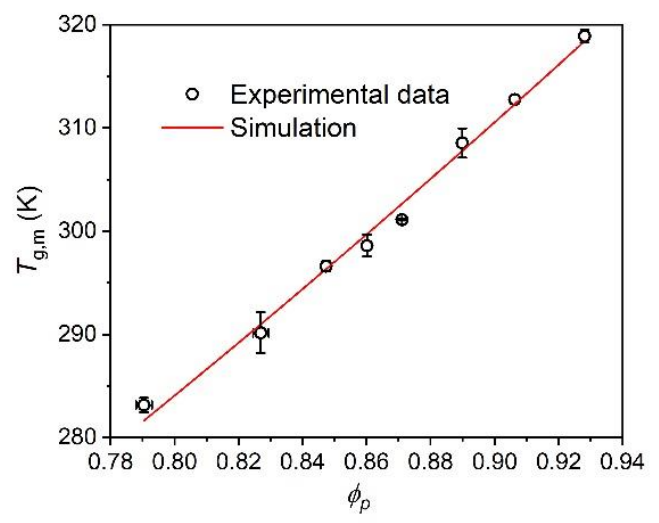

Fig. 6: Comparison of simulation and experimental data of the average glass transition temperature of the free PU films, $T_{\mathrm{g}, \mathrm{m}}$, against the PU solids volume fraction, $\phi_{\mathrm{s}}$ of cured coatings. $T_{\mathrm{g}, \mathrm{s}}=131.9 \mathrm{~K}, T_{\mathrm{g}, \mathrm{p}}=339.4 \mathrm{~K}$, and $K_{\alpha}=0.687$. Standard deviations are shown with error bars.

\section{Pendulum hardness and the loss factor}

For a coating, the pendulum hardness is, in general, proportional to the reciprocal of the damping capacity $^{24,25}$, the latter of which is the ability to absorb vibration by internal friction, thereby converting mechanical energy into heat. Commonly, the loss factor, also known as the damping coefficient (i.e., the ratio of the energy dissipated per cycle to the energy stored ${ }^{26}$ ) is used to characterize damping capacity and in Figure 7, the pendulum hardness is plotted against the reciprocal of the loss factor.

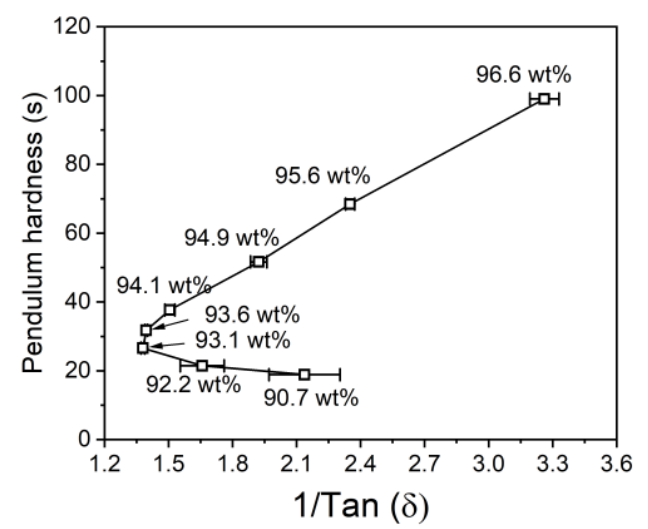

Fig. 7: The pendulum hardness plotted against the reciprocal of the loss factor, i.e., 1/Tan $(\delta)$, at 23.2 ${ }^{\circ} \mathrm{C}$ with solids concentrations of PU films indicated at each data point. To obtain the loss 
factor, linear interpolation between two data points, adjacent to $23.2{ }^{\circ} \mathrm{C}$, in Fig. 4 (b) were used. The pendulum hardness was estimated using the three-order polynomial fit $\left(\mathrm{R}^{2}=0.9994\right)$ of the data in Fig. 3(b). Standard deviations are provided with error bars.

A proportional increase of pendulum hardness can be observed with increasing values of the reciprocal loss factor for solids concentrations above $93.6 \mathrm{wt} \%$. However, when the solids concentration is lower than $93.1 \mathrm{wt} \%$, the hardness declines as the reciprocal value of the loss factor increases. This decline of hardness is probably caused by a change in contact area between the pendulum pivot ball and the PU film. When the solids concentration is lower than $93.1 \mathrm{wt} \%$, the glass transition temperature is below $23.2{ }^{\circ} \mathrm{C}$ (the curing temperature, see Fig. 5), and the PU films are in the rubbery state, providing a significantly higher contact area. In the pendulum hardness test, pendulum attenuation is mainly attributed to the energy dissipation caused by viscous flow of the solid under the pendulum pivot and the energy dissipation is proportional to the contact area ${ }^{27}$. Despite the higher value of the reciprocal loss factor, the increase of contact area increases the pendulum attenuation and thus reduces the pendulum hardness when the coating films are in the rubbery state. However, when the films are in the glassy region, the change of the contact area can be neglected so that the pendulum hardness exhibits an inversely proportional increase with the loss factor. Therefore, it can be concluded that pendulum hardness is only inversely proportional to the loss factor when the glass transition temperature of the PU coating is higher than the environmental temperature.

\subsection{Effect of catalyst concentration on hardness of coatings}

Organotin compounds are the most common and reactive catalysts for the urethane formation reactions ${ }^{28}$. The influence of catalyst concentration on the curing of the PU films is shown in Fig. 8. 
(a)

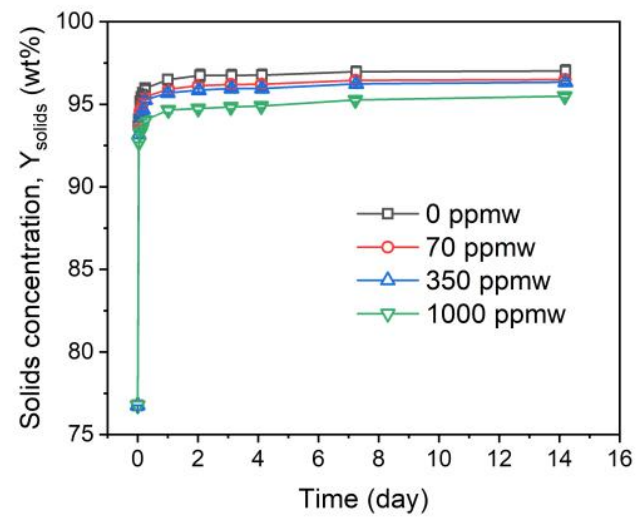

(c)

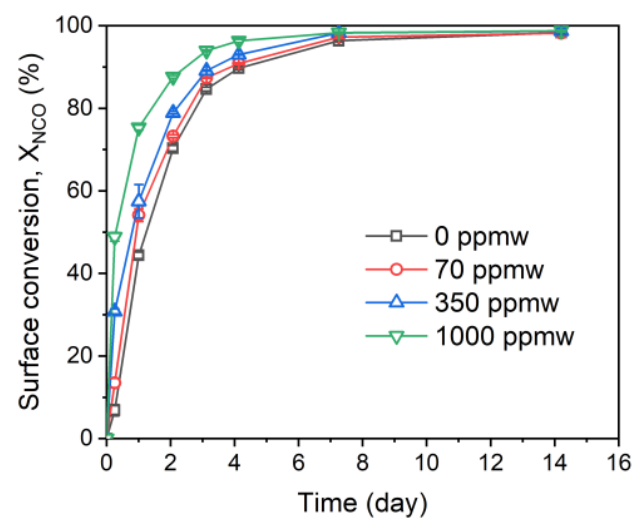

(e)

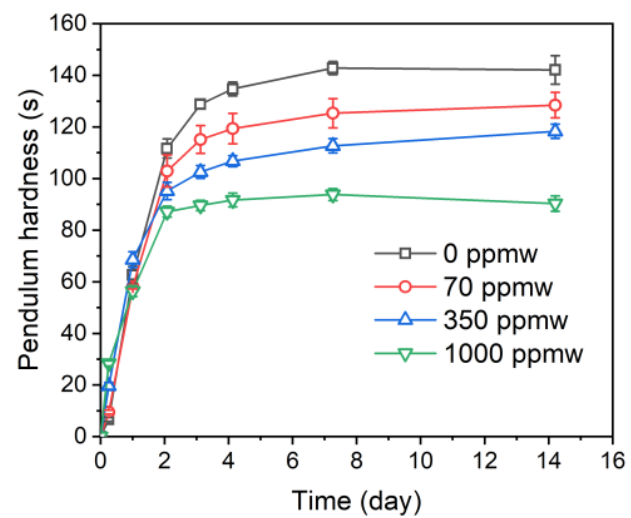

(b)

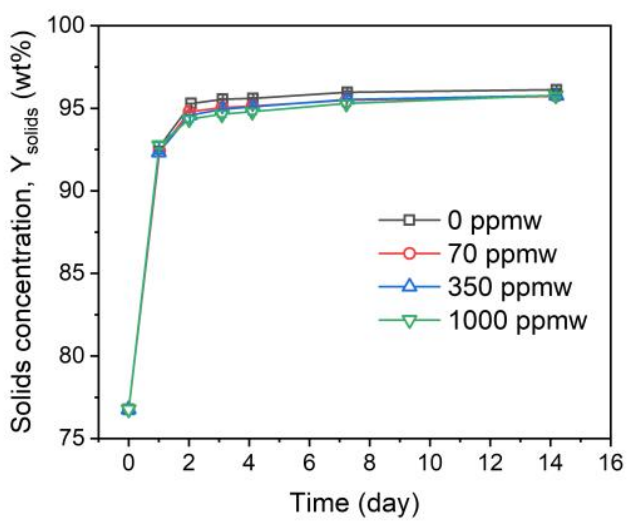

(d)

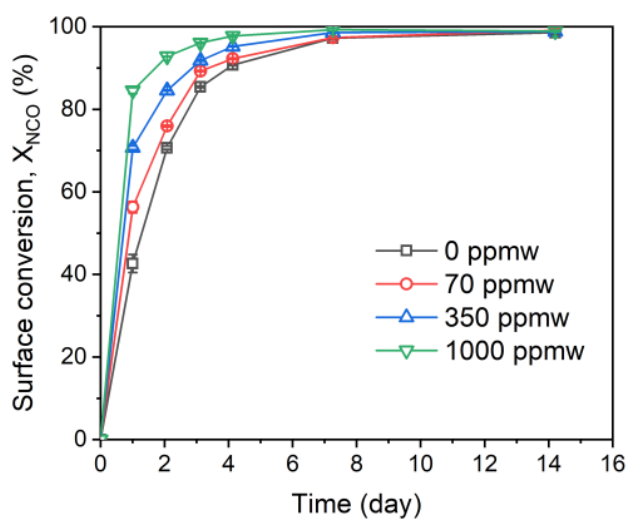

(f)

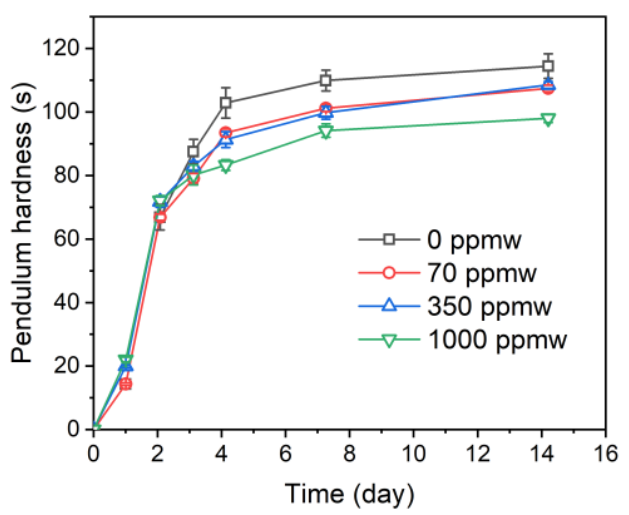

Fig. 8: Influence of catalyst concentration on the curing of PU films: The increase of solids concentration during solvent evaporation (a) the CR condition and (b) the CC-CR condition; The surface conversion of isocyanate groups in the coating (c) the CR condition and (d) the CC-CR condition; The hardness development of the coating (e) the CR condition and (f) the CC-CR condition. Standard deviations are shown with error bars in all six plots. 
With a higher amount of organotin catalyst, the rate of the curing reaction between isocyanates and polyols is expected to increase (until a potential saturation). This can be clearly seen from Fig. 8(c) and (d) where PU samples with 1000 ppmw catalyst has the fastest consumption of isocyanates while PU samples without catalyst have the lowest reaction rate. However, a fast curing reaction has a negative effect on the solvent evaporation process in that increases the residual solvent, which can be seen in Fig. 8(a) and (b). A fast curing reaction shortens the curing time of PU films to the glassy state, where the solvent evaporation becomes diffusion-controlled. In comparison with the solvent evaporation under the $\mathrm{CR}$ condition, the amount of organotin catalyst has less influence under the CC-CR condition. Under the evaporation-suppressed condition, the buildup of solvent in the environment plays a more important role on controlling the solvent evaporation rate. Therefore, less of a difference of final solids concentration is observed under the CC-CR condition (Fig. 8(b)) compared to that under the CR condition (Fig. $8(\mathrm{a}))$.

Despite the lowest hardness after curing for one day (Fig. 8(e) and (f)), the PU films without catalyst have the highest hardness after curing for 14 days. A low catalyst concentration slows down the curing reaction, but helps the solvent evaporation process and minimize the amount of residual solvent. When a sufficient curing time (more than one day) is allowed, it is recommended to cure a PU film without catalyst.

\section{Conclusions}

A quantitative analysis of the simultaneous solvent evaporation, chemical curing, glass transition temperature, and hardness development of a series of PU coatings under freely evaporating and evaporation-suppressed conditions was conducted.

Under the evaporation-suppressed conditions, the solvent evaporation rate goes down, while the rate of curing reactions increase. The overall result, due to a solvent plasticizing effect, is that the glass transition temperature and the hardness of the coating both decrease.

The Kelley-Bueche equation was successfully used to simulate the coating glass transition temperature as a function of the PU volume fraction, and provided insight into the hardness reduction mechanism. In addition, a higher concentration of organotin catalyst was observed to have a negative effect on the final coating hardness. 
In a practical situation, to obtain the required hardness of thermoset organic coatings, it is important to ensure sufficient evaporation of the solvent(s). This can be done with adequate evaporation rates and by reducing the catalyst concentration in the coating. Ventilation conditions can also be adjusted to help the curing process, but this only works prior to reaching the vitrification point of the coating. Strategies with adequate air flow and exchange rates, and sufficiently high curing temperatures can be used to ensure the right solvent evaporation rates.

\section{Acknowledgements}

Financial support from the Hempel Foundation to CoaST (The Hempel Foundation Coatings Science and Technology Centre) is gratefully acknowledged.

\section{References}

1 (Journal Article) Sørensen, PA, Kiil, S, Dam-Johansen, K, Weinell, CE, "Anticorrosive coatings: A review." J. Coatings Technol. Res., 6 (2) 135-176 (2009).

2 (Journal Article) Yi, C, Rostron, P, Vahdati, N, Gunister, E, Alfantazi, A, "Curing kinetics and mechanical properties of epoxy based coatings: The influence of added solvent." Prog. Org. Coatings, 124 (May) 165-174 (2018).

3 (Journal Article) Kiil, S, "Quantification of simultaneous solvent evaporation and chemical curing in thermoset coatings." J. Coatings Technol. Res., 7 (5) 569-586 (2010).

4 (Journal Article) Kiil, S, "Mathematical modelling of simultaneous solvent evaporation and chemical curing in thermoset coatings: A parameter study." Prog. Org. Coatings, 70 (4) 192-198 (2011).

5 (Journal Article) Esmaeilpour, M, Niroumand, B, Monshi, A, Salahi, E, Ramezanzadeh, B, "Effects of curing condition on the surface characteristics of two-pack polyurethane coatings containing low surface energy additive." Soft Mater., 13 (3) 144-149 (2015).

6 (Journal Article) Vessot, S, Andrieu, J, Laurent, P, Galy, J, Gérard, JF, "Air convective drying and curing of polyurethane-based paints on sheet molding compound surfaces." J. Coatings Technol., 70 (882) 67-76 (1998).

7 (Journal Article) Huang, Z, Ma, X, Qiao, Z, Wang, S, Jing, X, "Pendulum hardness of polyurethane coatings during curing." Pigment Resin Technol., 43 (5) 271-276 (2014).

8 (Journal Article) Tambe, SP, Jagtap, SD, Choudhari, RN, Mallik, BP, "Influence of crosslinking agents and curing condition on the performance of epoxy coating." Pigment Resin 
Technol., 45 (5) 354-362 (2016).

9 (Journal Article) Dušková-Smrčková, M, Dušek, K, "Processes and states during polymer film formation by simultaneous crosslinking and solvent evaporation." J. Mater. Sci., 37 (22) 4733-4741 (2002).

10 (Journal Article) Yamamura, M, Horiuchi, K, Kajiwara, T, Adachi, K, "Decrease in solvent evaporation rate due to phase separation in polymer films." AIChE J., 48 (11) 2711-2714 (2002).

11 (Journal Article) Dušek, K, Dušková-Smrčková, M, "Network structure formation during crosslinking of organic coating systems." Prog. Polym. Sci., 25 (9) 1215-1260 (2000).

12 (Journal Article) Shafiu Kamba, A, Ismail, M, Tengku Ibrahim, TA, Zakaria, ZAB, "Synthesis and characterisation of calcium carbonate aragonite nanocrystals from cockle shell powder (Anadara granosa)." J. Nanomater., 2013 (2013). doi:10.1155/2013/398357.

13 (Journal Article) Miller, FA, Wilkins, CH, "Infrared Spectra and Characteristic Frequencies of Inorganic Ions." Anal. Chem., 24 (8) 1253-1294 (1952).

14 (Journal Article) DIN, E, "1522: 2007-04 Paints and varnishes--Pendulum damping test (ISO 1522: 2006)." Ger. version EN ISO, 1522 (2006).

15 (Journal Article) Nacas, AM, Vidotti, SE, Chinellato, AC, Santos, DJ do., "The role of polyol reaction catalysts in the cure kinetics and mechanical behavior of polyurethane adhesives." J. Adhes., 00 (00) 1-13 (2018).

16 (Journal Article) Ginic-Markovic, M, Choudhury, NR, Matisons, JG, Williams, DRG, "Characterization of polyurethane coatings using thermoanalytical techniques." J. Therm. Anal. Calorim., 59 (1) 409-424 (2000).

17 (Journal Article) Elwell, MJ, Ryan, AJ, Grunbauer, HJM, VanLieshout, HC, "An FT IR study of reaction kinetics and structure development in model flexible polyurethane foam systems." Polymer (Guildf)., 37 (8) 1353-1361 (1996).

18 (Journal Article) Berry, NG, D’Almeida, JRM, Barcia, FL, Soares, BG, "Effect of water absorption on the thermal-mechanical properties of HTPB modified DGEBA-based epoxy systems." Polym. Test., 26 (2) 262-267 (2007).

19 (Journal Article) Nogueira, P, Ramírez, C, Torres, A, Abad, MJ, Cano, J, López, J, et al., "Effect of water sorption on the structure and mechanical properties of an epoxy resin system." J. Appl. Polym. Sci., 80 (1) 71-80 (2001). 
20 (Journal Article) Kelley, FN, Bueche, F, "Viscosity and glass temperature relations for polymer-diluent systems." J. Polym. Sci., 50 (154) 549-556 (1961).

21 (Journal Article) Fried, JR, "Polymer science and technology." Prentice Hall, 2014.

22 (Journal Article) Petrobras Europe Ltd, "Solvent naphtha (petroleum), light aromatic safety data sheet." (2012). http://sites.petrobras.com.br/minisite/reach/downloads/fichastecnicas/Ingles/PEL/PbR0002i_EN_v00_PEL_AB9 (eSDS).pdf (accessed 5 Jun 2019).

23 (Journal Article) Garfield, LJ, Petrie, SE, "Viscosity and glass-transition behavior of polymer-diluent systems." J. Phys. Chem., 68 (7) 1750-1754 (1964).

24 (Journal Article) Sato, K, "The hardness of coating films." Prog. Org. Coatings, 8 (1) 1-18 (1980).

25 (Journal Article) Ma, X, Qiao, Z, Huang, Z, Jing, X, "The dependence of pendulum hardness on the thickness of acrylic coating." J. Coatings Technol. Res., 10 (3) 433-439 (2013).

26 (Journal Article) Menard, KP, Menard, NR, "Dynamic Mechanical Analysis in the Analysis of Polymers and Rubbers." 2015 doi:10.1002/0471440264.pst102.pub2.

27 (Journal Article) Fox, PG, Freeman, IB, "What does the pendulum hardness test measure?" J. Mater. Sci., 14 (1) 151-158 (1979).

28 (Journal Article) van der Weij, FW, "Kinetics and Mechanism of Urethane Formation Catalyzed By Organotin Compounds - 2. the Reaction of Phenyl Isocyanate With Methanol in Dmf and Cyclohexane Under the Action of Dibutylin Diacetate." J. Polym. Sci. A1., 19 (12) 3063-3068 (1981). 